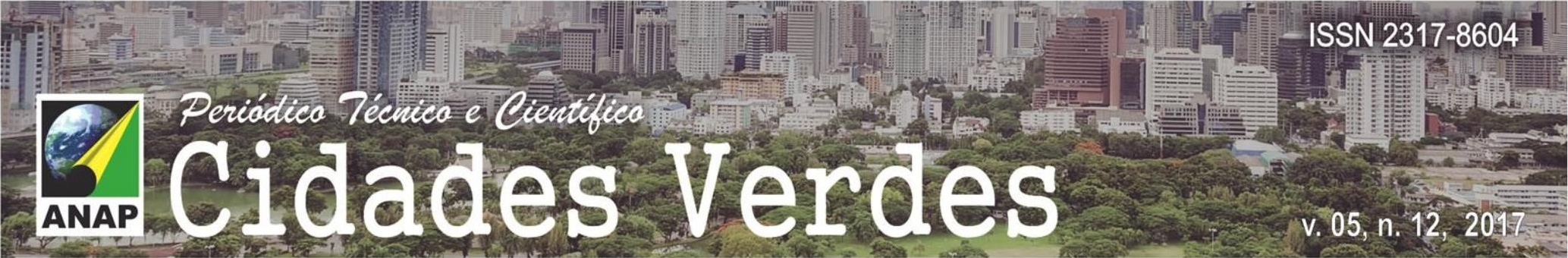

\title{
Proposta de Índice de Potencial de Sustentabilidade Urbana: Estudo de Caso em Pedra Branca-SC
}

Proposal of Urban Sustainability Potential Index: A Case Study In Pedra Branca-SC Propuesta de índice de Potencial de Sustentabilidad Urbana: estudio de caso en Pedra Branca-SC

\section{Raíssa Martins Amadeo} Mestranda, UEM, Brasil. ra.amadeo@gmail.com

Paulo Fernando Soares Professor Doutor, UEM, Brasil. pfsoares@uem.br

Igor José Botelho Valques Professor Doutor, UEM, Brasil. ijbvalques@gmail.com 


\section{RESUMO}

Muitos estudiosos defendem a implantação de cidades com características inovadoras, dentre elas: cidades compactas, conectadas, dotadas de áreas verdes, bairros multifuncionais, e que privilegiem o pedestre e transporte público ao invés dos automóveis, o que deu origem ao termo cidade sustentável. Em diversos locais do globo, cidades são autointituladas como sustentáveis, entretanto nem sempre atendem requisitos para isso. Mensurar a sustentabilidade urbana tornou-se uma ação de extrema importância no que diz respeito a auxiliar gestores municipais nas tomadas de decisões. Assim, o presente estudo teve como objetivo propor um Índice de Sustentabilidade Urbana, a fim de que seja possível saber em quais aspectos a cidade é sustentável e em quais necessita de ações estratégicas para melhorarias de caráter socioambientais. As áreas escolhidas para compor o Índice foram: Infraestrutura, mobilidade, meio ambiente, governança, energia, economia e pessoas. Para cada uma, foram selecionados indicadores qualitativos, a partir do Programa Cidades Sustentáveis, legislação (quando existente) ou da literatura, aos quais foram atribuídos pesos conforme as características estivessem presentes (5pts) ou ausentes (1pt) na cidade, podendo sua nota final variar de 0 a 100 e classificar seu planejamento urbano como insustentável (0-25pts); regular (26-50pts); bom (51-75pts) ou potencialmente sustentável (76-100pts). Posteriormente, por meio de entrevista responsáveis pelo planejamento urbano do empreendimento, aplicou-se o Índice ao projeto do bairro Pedra Branca em Santa Catarina, o qual obteve nota 92, sendo considerado potencialmente sustentável.

PALAVRAS-CHAVE: Indicadores de Sustentabilidade. Planejamento Urbano. Sustentabilidade Urbana.

\section{ABSTRACT}

Many scholars defend the implantation of cities with innovative characteristics, among them: compact cities, connected, equipped with green areas, multifunctional neighborhoods, and privileging the pedestrian and public transportation instead of automobiles, which gave rise to the term sustainable city. In several places around the globe, cities are self-labeled as sustainable, though they do not always meet the requirements. Measuring urban sustainability has become an extremely important action in assisting municipal managers in decision-making. Thus, the present study aimed to propose an Urban Sustainability Index, so that it is possible to know in which aspects the city is sustainable and in which it needs strategic actions for social and environmental improvements. The areas chosen to compose the Index were: Infrastructure, mobility, environment, governance, energy, economy and people. For each one, qualitative indicators were selected from the Sustainable Cities Program, legislation (when existing) or literature, which were assigned weights according to whether the characteristics were present (5pts) or absent (1pt) in the city, and their final grade vary from 0 to 100 and classify their urban planning as unsustainable (0-25pts); regular (26-50pts); good (51-75pts) or potentially sustainable (76-100pts). Subsequently, through an interview responsible for the urban planning of the project, the Index was applied to the project of the Pedra Branca neighborhood in Santa Catarina, which obtained a grade 90, being considered potentially sustainable.

KEY WORDS: Sustainability Indicators. Urban planning. Urban Sustainability.

\section{RESUMEN}

Muchos estudiosos defienden la implantación de ciudades con características innovadoras, entre ellas: ciudades compactas, conectadas, dotadas de áreas verdes, barrios multifuncionales, y que privilegien el peatón y transporte público en lugar de los automóviles, lo que dio origen al término ciudad sostenible. En diversos lugares del globo, las ciudades son autointituladas como sostenibles, sin embargo no siempre cumplen requisitos para ello. La medición de la sostenibilidad urbana se ha convertido en una acción de extrema importancia en lo que se refiere a ayudar a los gestores municipales en las tomas de decisiones. Así, el presente estudio tuvo como objetivo proponer un Índice de Sustentabilidad Urbana, a fin de que sea posible saber en qué aspectos la ciudad es sostenible y en qué necesita acciones estratégicas para mejoras de carácter socioambiental. Las áreas elegidas para componer el índice fueron: Infraestructura, movilidad, medio ambiente, gobernanza, energía, economía y personas. Para cada uno, indicadores cualitativos fueron seleccionados de la Programa de ciudades sostenibles, la legislación (cuando exista) o de la literatura, a la que los pesos fueron asignados de acuerdo a las características estaban presentes (5 puntos) o ausente (1 pt) en la ciudad, y su grado final de 0 a 100 y clasificar su planificación urbana como insostenible (025pts); (26-50pts); (51-75pts) o potencialmente sostenible (76-100pts). Posteriormente, por medio de entrevistas responsables por la planificación urbana del emprendimiento, se aplicó el Índice al proyecto del barrio Pedra Branca en Santa Catarina, el cual obtuvo nota 92, siendo considerado potencialmente sustentable.

PALABRAS CLAVE: Indicadores de Sostenibilidad. Planificación Urbana. Sostenibilidad Urbana. 


\section{INTRODUÇÃO}

Após uma grande concentração sem planejamento da população em áreas urbanas, alavancada pelo fenômeno da Revolução Industrial, surgiram muitos conflitos socioambientais como ocupações irregulares, aumento da poluição e degradação ambiental, formação de subúrbios sem infraestrutura adequada, maior geração de emissões atmosféricas, geração de maior quantidade de resíduos, aumento da violência, dentre outros.

O conceito de desenvolvimento sustentável criado durante a Conferência das Nações Unidas sobre o meio Ambiente e Desenvolvimento em 1992 prega que a sociedade atual deve utilizar os recursos naturais para suprir suas necessidades sem comprometer as gerações futuras. Neste contexto, a preocupação com o meio ambiente vem crescendo cada vez mais e alcançou a realidade urbana, pois nas cidades é que se encontram os maiores desafios e obstáculos para um desenvolvimento sustentável.

$\mathrm{Na}$ tentativa de trazer o conceito da sustentabilidade da teoria para a realidade, urbanistas e gestores procuraram propor e integrar ações e políticas públicas no planejamento urbano com o objetivo de melhorar a qualidade de vida nas cidades e reduzir a pressão sobre os recursos naturais, o que deu origem as cidades sustentáveis.

Algumas das características que uma cidade sustentável possui são: justiça, beleza, criatividade, ecologia, infraestruturas, além de ser compacta, policêntrica e diversificada (ROGERS; GUMUCHDJIAN, 2001)

Uma cidade sustentável visa promover a melhoria da qualidade de vida, incentivando a equidade social e cultura, resguardando os princípios da vida e biodiversidade por meio da minimização dos impactos ambientais, utilizando seus recursos de maneira eficaz, criando oportunidades econômicas e responsabilidades para todos (CIB, 2000).

Tendo em vista a atual necessidade de se promover o desenvolvimento sustentável, é importante mensurar a sustentabilidade urbana a fim de auxiliar gestores frente a tomadas de decisões com a observação de lacunas no planejamento urbano que exigem ações mitigadoras. Assim, uma maneira de estimar a sustentabilidade urbana é por meio da utilização de indicadores.

Os indicadores de sustentabilidade podem constituir uma importante ferramenta de gestão ambiental, econômica, social, cultural e institucional à medida que consigam orientar e mensurar a sustentabilidade, avaliando o comprometimento de instituições com o desenvolvimento sustentável (ALVES et al.; 2016).

Neste sentido, a presente pesquisa teve por objetivo propor indicadores das principais dimensões de uma cidade para constituir um Índice de Sustentabilidade Urbana e posteriormente aplica-lo em um dos exemplos de projetos brasileiros concebidos nos moldes de cidade sustentável, o bairro Pedra Branca situado em Palhoça no estado de Santa Catarina. 


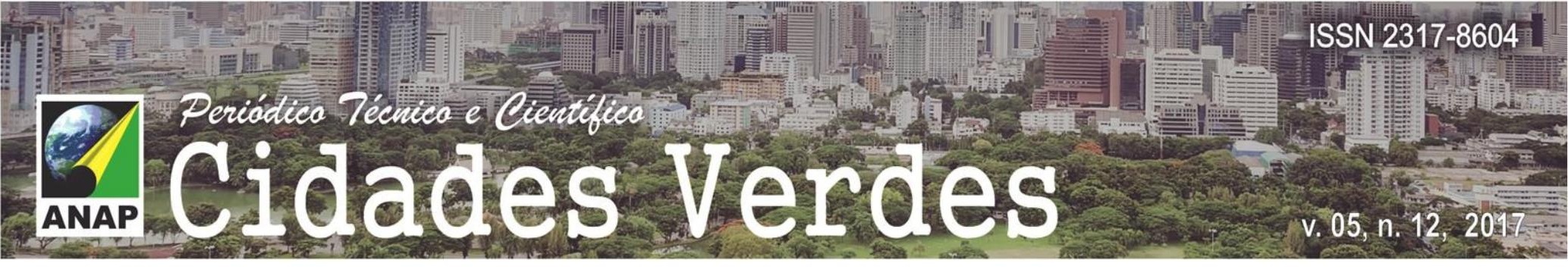

\section{OBJETIVOS}

A pesquisa contemplada neste artigo teve como objetivo propor um Índice capaz de mensurar a sustentabilidade urbana e, posteriormente, avaliar sua eficiência aplicando-o ao empreendimento Pedra Branca em Santa Catarina.

\subsection{OBJETIVOS ESPECÍFICOS}

- Definir indicadores de sustentabilidade urbana;

- Propor um Índice de mensuração da Sustentabilidade Urbana;

- Aplicar o Índice proposto ao projeto do empreendimento Pedra Branca-SC;

- Classificar a sustentabilidade urbana de Pedra Branca-SC

\section{MÉTODO DE ANÁLISE}

A pesquisa foi realizada em duas etapas, sendo a primeira a formulação do índice e seus indicadores e a segunda um estudo de caso aplicando o índice desenvolvido no bairro cidade Pedra Branca- SC. Inicialmente realizou-se uma pesquisa bibliográfica, para obter informações a respeito do tema da pesquisa, bem como sobre os índices e indicadores de sustentabilidade urbana existentes.

A pesquisa bibliográfica é desenvolvida por meio de materiais previamente elaborados como livros de leitura corrente, dicionários, enciclopédias, anuários, almanaques bem como revistas ou jornais científicos (GIL, 1991).

Ainda de acordo com o referido autor, esta pesquisa é classificado como exploratória, que inclui levantamento bibliográfico, entrevistas e estudos de caso. É também, uma pesquisa descritiva, pois relata características de um objeto de estudo e estabelece relações entre variáveis.

\subsection{FORMULAÇÃO DA PROPOSTA DO ÍNDICE DE SUSTENTABILIDADE}

\subsubsection{Indicadores De Sustentabilidade Urbana Utilizados}

Visando estabelecer possíveis parâmetros observando os princípios do desenvolvimento sustentável, estabeleceu-se quatro dimensões sinergéticas principais de uma cidade para compor o Índice de Sustentabilidade Urbana: meio ambiente; mobilidade e acessibilidade; social e econômica.

Partindo da necessidade de fundamentação da escolha de indicadores, foram pesquisados indicadores na plataforma digital do Programa Cidades Sustentáveis (PCS).

O PCS estabelece indicadores paras as seguintes áreas: governança; bens naturais comuns; equidade, justiça social e cultura de paz; gestão local para a sustentabilidade; planejamento e desenho urbano; cultura para a sustentabilidade; educação para a sustentabilidade e 


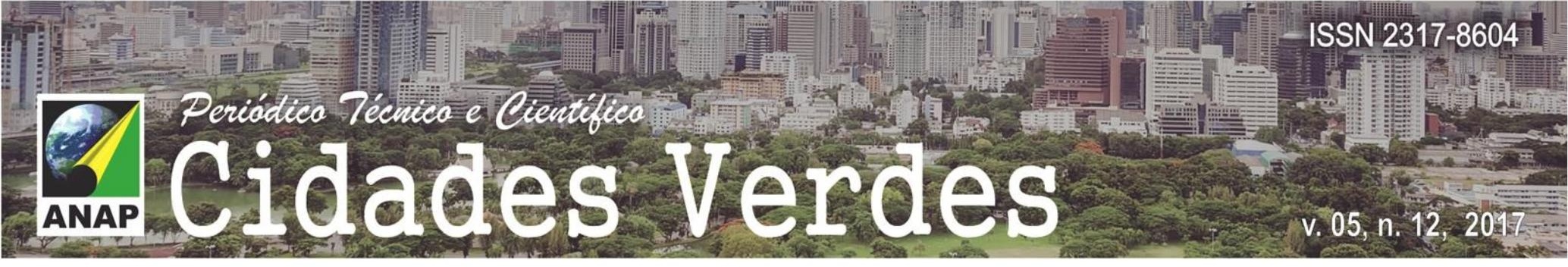

qualidade de vida; economia local dinâmica, criativa e sustentável; consumo responsável e opções de estilo de vida; melhor mobilidade, menos tráfego; ação local para saúde e por fim, ações locais com impacto global (PROGRAMA CIDADES SUSTENTÁVEIS, 2016).

Neste contexto, foi possível por meio da escolha de alguns itens dessas áreas, denominados neste estudo de indicadores de base, formular cinco indicadores síntese para cada dimensão da cidade, com vistas a facilitar sua aplicação na prática. Tais indicadores de base e seus respectivos indicadores sínteses estão descritos no quadro 1 :

Quadro 1: Indicadores da dimensão ambiental e possíveis metas.

\begin{tabular}{|c|c|c|}
\hline Dimensão & Indicadores De Base (PCS) & Indicador Síntese \\
\hline \multirow{5}{*}{ Ambiental } & $\begin{array}{l}\text { Consumo de energia produzida por fontes renováveis - Meta: Fazer } \\
\text { o levantamento das fontes da energia consumida pelo município e } \\
\text { incentivar a geração por fontes renováveis. }\end{array}$ & $\begin{array}{l}\text { Utilização de fontes de } \\
\text { energia renováveis }\end{array}$ \\
\hline & $\begin{array}{l}\text { Área verde por habitante - A Organização Mundial de Saúde (OMS) } \\
\text { recomenda um mínimo de } 12 \mathrm{~m}^{2} \text { de área verde por habitante. }\end{array}$ & Áreas verdes \\
\hline & $\begin{array}{l}\text { Abastecimento público de água potável na área urbana - Meta: } \\
100 \% \text { da população urbana do município atendida pelo } \\
\text { abastecimento público de água potável. } \\
\checkmark \quad \text { Rede de esgoto Porcentagem de domicílios urbanos sem ligação } \\
\text { com a rede de esgoto sobre o total de domicílios. Meta: } 100 \% \\
\text { de domicílios urbanos ligados à rede de esgoto. } \\
\checkmark \quad \text { Resíduos depositados em aterros sanitários Porcentagem do } \\
\text { lixo da cidade que é depositada em aterros sanitários por ano. }\end{array}$ & Saneamento básico \\
\hline & $\begin{array}{l}\text { Total de emissões de CO2 equivalente per capita Inventário } \\
\text { detalhado das emissões que impactam sobre o clima do planeta. } \\
\text { Meta: Fazer inventário de emissões e estabelecer metas de } \\
\text { redução. }\end{array}$ & $\begin{array}{l}\text { Qualidade do ar } \\
\text { (redução de emissões e } \\
\text { monitoramento) }\end{array}$ \\
\hline & $\begin{array}{l}\text { Edifícios novos e reformados que têm certificação de } \\
\text { sustentabilidade ambiental - Meta: Implementar critérios de } \\
\text { sustentabilidade para todas as novas construções e as reformas da } \\
\text { cidade considerando as melhores práticas e certificações nacionais } \\
\text { e internacionais. }\end{array}$ & $\begin{array}{l}\text { Construções com } \\
\text { certificação ambiental }\end{array}$ \\
\hline
\end{tabular}

Fonte: ADAPTADO DE PROGRAMA CIDADES SUSTENTÁVEIS, 2016.

Os indicadores da dimensão Mobilidade e Acessibilidade estão descritos no quadro 2:

Quadro 2: Indicadores da dimensão Mobilidade e Acessibilidade e possíveis metas.

\begin{tabular}{|c|c|c|}
\hline Dimensão & Indicadores De Base (PCS) & Indicador Síntese \\
\hline \multirow{5}{*}{$\begin{array}{l}\text { Mobilidade e } \\
\text { Acessibilidade }\end{array}$} & Calçadas consideradas adequadas às exigências legais & $\begin{array}{l}\text { Passeio público } \\
\text { adequado }\end{array}$ \\
\hline & $\begin{array}{l}\text { População residente num um raio de } 300 \text { metros de algum } \\
\text { transporte que passa com a frequência necessária }\end{array}$ & Uso misto do solo \\
\hline & $\begin{array}{l}\text { Frota de ônibus com acessibilidade para pessoas com deficiência. } \\
\text { Meta: } 100 \% \text { da frota de ônibus com acessibilidade para pessoas } \\
\text { com deficiência. }\end{array}$ & $\begin{array}{l}\text { Acessibilidade para } \\
\text { cadeirantes }\end{array}$ \\
\hline & Ciclovias exclusiva & Ciclovias \\
\hline & $\begin{array}{l}\text { Índice de Congestionamentos Média aritmética anual dos } \\
\text { congestionamentos, em km, nos horários de pico (manhã e tarde). }\end{array}$ & $\begin{array}{l}\text { Acesso a transporte } \\
\text { público adequado }\end{array}$ \\
\hline
\end{tabular}

Fonte: ADAPTADO DE PROGRAMA CIDADES SUSTENTÁVEIS, 2016. 


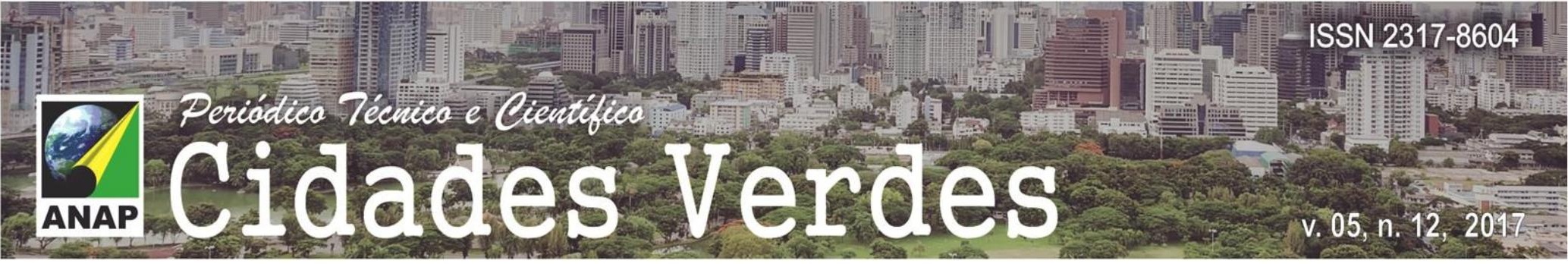

A dimensão social está descrita no quadro 3:

Quadro 3: Indicadores da dimensão social e possíveis metas

\begin{tabular}{|c|c|c|}
\hline Dimensão & Indicadores de base (PCS) & Indicador síntese \\
\hline \multirow{5}{*}{ Social } & $\begin{array}{l}\text { Unidades Básicas de Saúde Número de unidades básicas públicas de } \\
\text { atendimento em saúde por dez mil habitantes. Meta: garantir, no } \\
\text { mínimo, uma UBS (Unidade Básica de Saúde) com Programa Saúde } \\
\text { da Família para cada dez mil habitantes, por menor unidade } \\
\text { administrativa, distribuídos de forma a garantir o acesso fácil e } \\
\text { rápido por toda a população. }\end{array}$ & Polos de Saúde \\
\hline & $\begin{array}{l}\text { Centros culturais, casas e espaços de cultura Número de centros } \\
\text { culturais, casas e espaços de cultura, por dez mil habitantes. Meta: } \\
\text { No mínimo um centro cultural a cada dez mil habitantes, por menor } \\
\text { unidade administrativa, distribuídos de forma a garantir o acesso } \\
\text { fácil e rápido por toda a população. }\end{array}$ & Diversidade cultural \\
\hline & $\begin{array}{l}\checkmark \text { Taxa de analfabetismo na população com } 16 \text { anos ou mais } \\
\text { Porcentagem da população analfabeta com } 16 \text { anos ou mais. } \\
\text { Meta: Erradicar o analfabetismo até } 2016 \text {. } \\
\checkmark \quad \text { Ensino superior concluído Porcentagem de pessoas de } 25 \text { anos } \\
\text { ou mais de idade com ensino superior concluído. }\end{array}$ & Polos Educacionais \\
\hline & População residente em aglomerados subnormais & $\begin{array}{c}\text { Habitações em locais } \\
\text { adequados }\end{array}$ \\
\hline & $\begin{array}{l}\text { Campanhas de educação cidadã Porcentagem de recursos } \\
\text { destinados a campanhas de educação cidadã sobre o total da verba } \\
\text { destinada à comunicação/publicidade do município. }\end{array}$ & $\begin{array}{l}\text { Minimização de } \\
\text { diferenças sociais } \\
\text { (cursos de capacitação, } \\
\text { políticas públicas etc.) }\end{array}$ \\
\hline
\end{tabular}

Fonte: ADAPTADO DE PROGRAMA CIDADES SUSTENTÁVEIS, 2016.

Por fim, os indicadores da dimensão econômica podem ser visualizados no quadro 4.

Quadro 4: Indicadores da dimensão econômica e possíveis metas.

\begin{tabular}{|c|l|c|}
\hline Dimensão & \multicolumn{1}{|c|}{ Indicadores De Base (PCS) } & Indicador Síntese \\
\hline & $\begin{array}{l}\text { Orçamento municipal investido em Ciência e Tecnologia: Meta: } \\
\text { atingir níveis mais elevados de produtividade das economias, por } \\
\text { meio da diversificação, modernização tecnológica e inovação, } \\
\text { inclusive por meio de um foco em setores de alto valor agregado e } \\
\text { intensivos em mão-de-obra. }\end{array}$ & Economia criativa \\
\cline { 2 - 4 } & $\begin{array}{l}\text { Desemprego Taxa média de desemprego no município. Referência } \\
\text { de Meta: Alcançar até 2015 o pleno emprego produtivo e trabalho } \\
\text { decente para todos, incluindo mulheres, negros e jovens. }\end{array}$ & Empregabilidade \\
\cline { 2 - 4 } & $\begin{array}{l}\text { Trabalho Infantil - Notificações de trabalho infantil Número de } \\
\text { notificações de trabalho infantil, registradas pelo Conselho Tutelar. } \\
\text { Meta: Erradicar o trabalho infantil imediatamente. }\end{array}$ & $\begin{array}{c}\text { Combate ao trabalho } \\
\text { infantil }\end{array}$ \\
\cline { 2 - 4 } & $\begin{array}{l}\text { Orçamento distribuído para as diferentes áreas da administração. } \\
\text { Meta: desenvolver instituições eficazes, responsáveis e } \\
\text { transparentes em todos os níveis. }\end{array}$ & $\begin{array}{c}\text { Investimentos nos } \\
\text { diversos setores } \\
\text { municipais }\end{array}$ \\
\cline { 2 - 4 } & $\begin{array}{l}\text { Existência no município de consórcio público, convênio de parceria, } \\
\text { apoio do setor privado ou de comunidades nas áreas de } \\
\text { desenvolvimento urbano, emprego/trabalho, educação, saúde, } \\
\text { cultura, turismo e meio ambiente }\end{array}$ & $\begin{array}{c}\text { Parcerias Público- } \\
\text { Privadas }\end{array}$ \\
\hline
\end{tabular}

Fonte: ADAPTADO DE PROGRAMA CIDADES SUSTENTÁVEIS, 2016. 


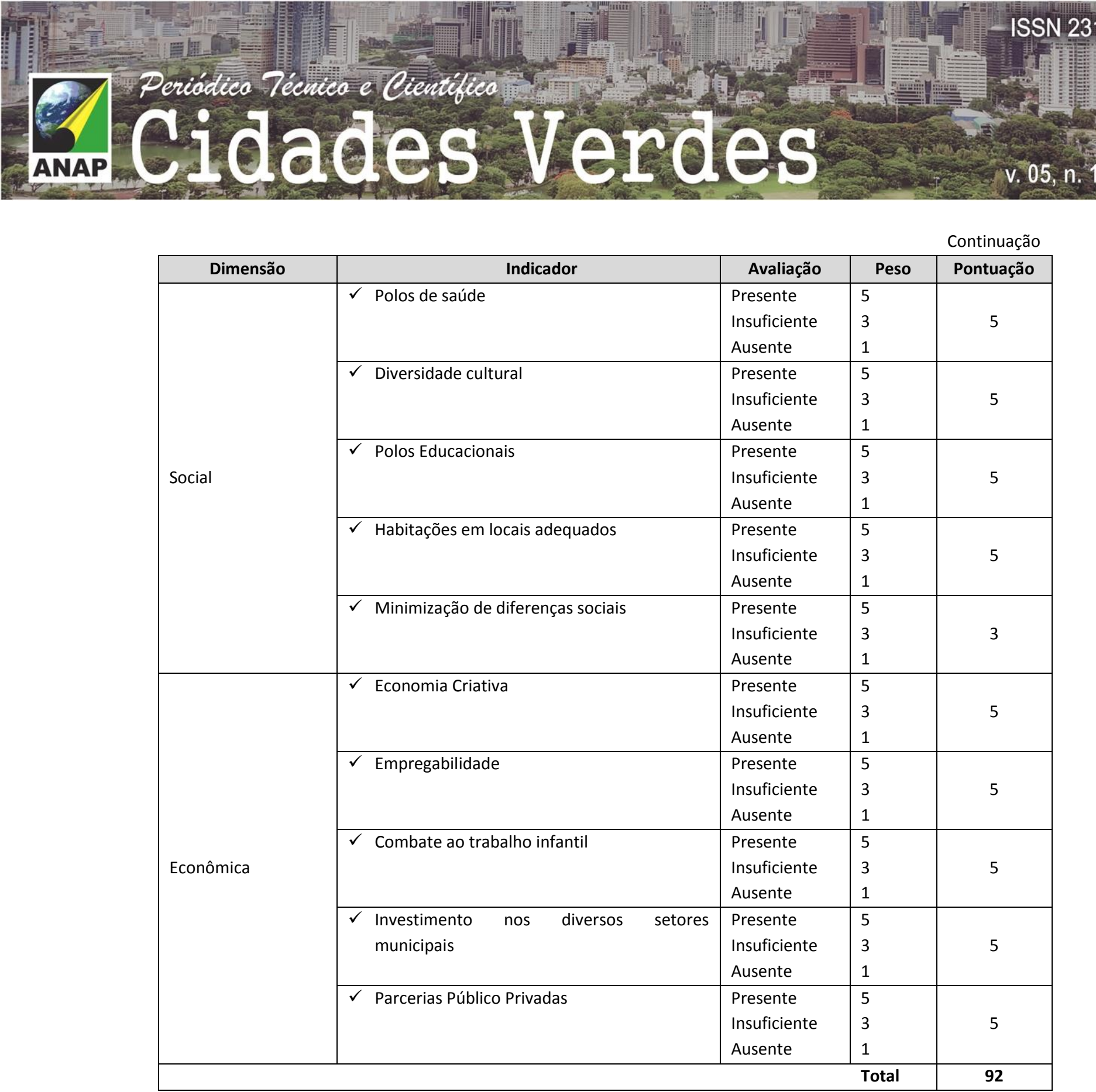

Fonte: AUTORES, 2017.

A nota final do Índice de Sustentabilidade Proposto aplicado ao projeto do planejamento urbano do bairro cidade Pedra Branca foi de 92 pontos, classificando-o como potencialmente sustentável, ou seja, a região apresenta características urbanas que promovem qualidade socioambiental, entretanto como o desenvolvimento sustentável não é um conceito estático, as ações urbanas devem acompanhar estas modificações, visando a melhoraria contínua do ambiente.

A dimensão meio ambiente atingiu 21 pontos, recebendo nota 1 para o indicador de utilização de energias renováveis, pois, este recurso ainda não é utilizado no bairro cidade.

A dimensão mobilidade e acessibilidade obteve 23 pontos, tendo em vista que o indicador acessibilidade para cadeirantes foi considerado insuficiente. A justificativa para tal, é que de acordo com o entrevistado, nem todos os horários de ônibus contam com este recurso. Já para 
os demais indicadores, a nota foi 5 considerando que um dos princípios norteadores do projeto é a prioridade ao pedestre e o mesmo apresenta calçadas amplas e semicobertas o que incentiva as caminhadas e menor utilização dos automóveis. Outra característica do projeto que contribui para menos emissões atmosféricas são as ciclovias.

Na dimensão social foram alcançados também 23 pontos, porque o indicador minimização de diferenças sociais foi considerado insuficiente, pois o que se observa em Pedra Branca é a presença de moradias de alto valor e especulação imobiliária, fato que acaba promovendo segregação social. Este indicador mostra que as expectativas dos princípios norteadores de diversidade de moradores e senso de comunidade não vem sendo atendidos.

Em Pedra Branca estão presentes aglomerados de residências de alto padrão, em sua maioria, construídas no setor central, as quais podem se sobressair sobre as moradias voltadas para classe média, apontando a existência de uma homogeneidade de moradores (RIBEIRO, 2010). Por fim, a dimensão econômica atingiu 25 pontos, pois, todos os indicadores estão presentes no bairro cidade. Uma explicação para tal é que o local está se tornando um polo empresarial de destaque, além de incentivar o empreendedorismo e a economia criativa. $O$ bairro conta com a presença do Instituto de Apoio à Inovação, Incubação e Tecnologia (INAITEC) e mais de 500 CNPJs (CADASTRO NACIONAL DE PESSOA JURÍDICA) registrados.

O bom desempenho geral mostra que ações urbanísticas locais reduzidas a escala de bairro podem contribuir para a promoção de um cenário com cidades mais sustentáveis além de diminuir significativamente a pressão sobre o meio ambiente e aumentar a qualidade socioeconômica.

O planejamento urbano na escala do bairro pode colaborar decisivamente para melhorar as condições de vida das comunidades urbanas e auxiliar na resolução dos problemas inerentes à administração municipal e setorial, tais como oferta de habitação, oportunidades de emprego e acesso e uso de bens e recursos.

Um planejamento urbano na escala de bairro, pode contribuir para a melhoria da qualidade de vida das cidades, além de solucionar problemas como oferta de moradia, oportunidades de emprego, acessibilidade bem como utilização de recursos naturais (MARINS, 2016).

$\mathrm{O}$ autor referido defende, ainda, o investimento no desenho e projeto urbano bem como a importância de definir parâmetros urbanísticos voltados para a escala de bairro.

Por meio da formulação e aplicação do Índice de Potencial de Sustentabilidade em Pedra Branca, foi possível perceber a dificuldade em definir tais parâmetros urbanísticos de sustentabilidade, porém a ferramenta utilizada se mostrou eficaz e aplicável tanto para localidades maiores como para bairros, atendendo a expectativa da presente pesquisa.

\section{CONCLUSÃO}

A nota final do Índice de Potencial de Sustentabilidade aplicado ao projeto do planejamento urbano do bairro cidade Pedra Branca foi de 92 pontos, classificando-o como potencialmente sustentável, ou seja, a região apresenta características urbanas que promovem qualidade socioambiental, entretanto como o desenvolvimento sustentável não é um conceito estático, 
